\title{
ASSESSMENT OF KNOWLEDGE AND ATTITUDE OF BRONCHIAL ASTHMA PATIENTS TOWARDS THEIR DISEASE
}

\author{
Gaude Gajanan ${ }^{1}$, Nicasia Fernandes 2 , Sindhury Avuthu³, Jyothi Hattiholi ${ }^{4}$
}

\author{
${ }_{1}^{1}$ Professor, Department of Pulmonary Medicine, KLE University's J. N. Medical College, Belgaum. \\ ${ }^{2}$ Assistant Professor, Department of Internal Medicine, Goa Medical College, Goa. \\ ${ }^{3}$ Senior Resident, Department of Pulmonary Medicine, KLE University's J. N. Medical College, Belgaum. \\ ${ }^{4}$ Assistant Professor, Department of Pulmonary Medicine, KLE University's J. N. Medical College, Belgaum.
}

\begin{abstract}
Asthma is chronic inflammatory, airway hyper-responsiveness, reversible disorder which occurs at any age, and requires special attention towards management of drug therapy. There is lack of patients awareness in having the complete knowledge about the disease, attitude towards disease management, medication adherence behavior and treatment outcomes. The objective of the present study was to assess the knowledge and attitude of the patients towards their disease in improving the outcome in asthma patients.
\end{abstract}

MATERIALS AND METHODS: This was a prospective, observational, questionnaire and hospital based study in a tertiary care teaching hospital at two different centers for a period of 12 months. The data was collected by face to face interview of outpatients and inpatients of Pulmonary Medicine and Internal Medicine departments by administering the questionnaires for the assessment of knowledge, attitude and adherence towards the bronchial asthma disease.

RESULTS: A total of 160 patients with confirmed diagnosis of bronchial asthma were included in this study, out of which male patients were $87(54.5 \%)$ and female patients $73(45.5 \%)$. On an average, each patient had already visited 3 doctors prior to coming to us. Out of 160 patients, $68 \%$ patients were ignorant regarding disease etiology, and another $54 \%$ patients were reluctant to accept the diagnosis of asthma. About $88 \%$ had the knowledge that lungs are affected by this disease. Another $44 \%$ opined that the medicines used for asthma can cause airways narrowing on long turn. Attitude of the patients varied greatly among the patients in this study. Regarding precipitating factors, $46 \%$ parents attributed the disease exacerbations due to multiple causes. The compliance rate in using inhalers for asthma was low (60\%), and many patients stopped medications in spite of proper advice regarding inhalational therapy.

CONCLUSION: This study concludes that the assessment of knowledge and attitude towards the disease of bronchial asthma patients is low. Controller medications and aerosol therapy is underused and unnecessarily blamed. Awareness raising strategies are needed in community. Patient education program should augment awareness about disease, eliminate social stigma, and misconcepts in the community regarding bronchial asthma.

KEYWORDS: Bronchial Asthma, Asthma Knowledge, Attitude, Practices, Compliance.

HOW TO CITE THIS ARTICLE: Gaude Gajanan, Nicasia Fernandes, Sindhury Avuthu, Jyothi Hattiholi. "Assessment of Knowledge and Attitude of Bronchial Asthma Patients towards their Disease". Journal of Evolution of Medical and Dental Sciences 2015; Vol. 4, Issue 90, November 09; Page: 15508-15514, DOI: 10.14260/jemds/2015/2219.

INTRODUCTION: Asthma is the most common chronic respiratory disorder among all age groups. In recent decades there have been striking advances in the clinical treatment of asthma. However, in spite of this, the prevalence and morbidity of asthma is increasing in many countries. ${ }^{1}$ This discrepancy between the scientific evidence and the continuing negative effect of asthma on society depends to a considerable extent on patient's behavior and doctors' performance. ${ }^{2}$ The overall burden of asthma in India is estimated at more than 15 million patients ${ }^{3}$. International efforts to reduce asthma morbidity and mortality have focused that on improving patient education and selfmanagement behavior. ${ }^{4}$

Financial or Other, Competing Interest: None.

Submission18-10-2015, Peer Review 19-10-2015,

Acceptance 26-10-2015, Published 06-11-2015.

Corresponding Author:

Dr. Gaude Gajanan,

Department of Pulmonary Medicine,

KLE University's J. N. Medical College, Belgaum-590010.

E-mail: gsgaude922@gmail.com

DOI:10.14260/jemds/2015/2219.
Prime reasons identified for poor prognosis are inadequate education to patients, poor adherence to the medications. ${ }^{5}$ Even the patients who are admitted repeatedly due to exacerbations due to asthma have a poor knowledge of asthma.

Many people with asthma perceive it as an intermittent illness that is not serious enough for daily treatment; it's only asthma. But it's both under-recognized and undertreated. Disease management of asthma includes knowledge of the disease, its treatment, and the effective use of different therapies; health care providers play a crucial role in empowering patients with the necessary skills and knowledge to manage asthma. ${ }^{6}$ With the lack of knowledge regarding asthma, the treatment regimen will fail because the patient is unaware of appropriate management steps or how to avoid triggers. Similarly, if a patient possesses adequate knowledge but lacks the confidence to manage episodes, or if the patient has an uncooperative attitude, treatment problems may arise.

Patient education is becoming an essential area of service provision, with our increasing population of people with chronic disease and conditions requiring long term management in the community. ${ }^{7}$ 
The effectiveness of drug therapy is largely influenced by noncompliance, which is believed to be affected by attitude towards drugs. The word attitude represents a summary of psychological object captured in dimensions such as good-bad, harmful-beneficial, pleasant, likeable and unlikeable. ${ }^{8}$ Compliance with therapeutic regimens in asthma is low. Education has been cited as an important component of any asthma management strategy, by improving asthma knowledge and changing behavior.9 Knowledge, attitudes, and beliefs of the patients towards bronchial asthma are recognized as being major determinants of health behavior. Currently there is little awareness about asthma in most of the developing countries, including India. Keeping in mind the fact that more and more people are now suffering from this disease, this lack of awareness is unfortunate. Patients' knowledge and attitude towards the disease on treatment can influence the medication adherence and eventually the therapeutic outcome. ${ }^{10}$

The present study is aimed to assess the knowledge and attitude of asthma patients towards their disease and treatment in a tertiary care hospital.

\section{OBJECTIVES:}

1. To assess the knowledge on bronchial asthma disease among the bronchial asthma patients.

2. To assess the patients attitude towards their disease and treatments options available for bronchial asthma.

MATERIALS AND METHODS: Population: Patients with bronchial asthma attending Pulmonary Medicine and Internal Medicine departments in two tertiary care hospitals at Belgaum and Goa. It was a prospective cross-sectional study conducted in outpatient department from July 2014 to June 2015. Sample size taken was 160 according to formula $\mathrm{n}=\mathrm{z} 21-\alpha / 2 \mathrm{P}(1-\mathrm{P}) / \mathrm{d} 2$.

Sample Size: The sample consisted of 160 patients.

METHODOLOGY: The prospective study, patients of bronchial asthma attending out and in-patient services of Departments of Pulmonary Medicine, KLES Dr. Prabhakar Kore Hospital and MRC, Belgaum, India, and Department of Internal Medicine, Goa Medical College, Goa, which are teaching and tertiary care referral hospitals, were evaluated during July 2014 to June 2015. Children below the age of 18 years with diagnosis of bronchial asthma were excluded from the study. Cases having other significant bronchopulmonary diseases associated with asthma, for example, tuberculosis, bronchiectasis, viral infections, bronchiolitis, and patients not willing to participate in the study were excluded from the study.

Diagnosis of asthma in selected was based upon GINA Guidelines. ${ }^{11}$ : Wheezing, high pitched whistling sound when breathing out with history of any of the following: Course worse particularly at night, recurrent wheeze, recurrent difficult breathing, recurrent chest tightness, family history of any allergy or bronchial asthma. The patients were evaluated for confirmation of diagnosis of bronchial asthma with the help of history, examination, and spirometry before and after bronchodilators inhalation.
An easily comprehensible questionnaire was designed; most questions were closed, with yes or no answers, although one was open ended. The questionnaire was designed to obtain information regarding the parent's perception of aetiology, triggers, asthma symptoms and effectiveness of treatment of asthma with focus on aerosol therapy, which included metered dose inhalers (MDI), dry powder inhalers (DPI), and nebulizer therapy. The patients were asked to identify and describe possible causes of asthma with no limit being placed on the number of responses. No attempt was made to correct a wrong answer or response until the completion of the interview.

The open ended question dealt with the parent's personal perception of the best possible management for asthma. The questions were designed to elicit a short answer or response to a multiple choice format. The questions dealt with the nature of illness, natural history, etiology, treatment, and prognosis. The patients were asked to identify and describe possible causes of asthma with no limit being placed on the number of responses. No attempt was made to correct a wrong answer or response until the completion of the interview.

From the detailed questionnaire, the following measureements were made for the study:

i) Asthma knowledge: For assessing asthma knowledge of the parents, the following questions were asked in detail: knowledge regarding asthma in their child; familiarity with the symptoms and characteristics of the disease; sport and asthma relationship, on impact of asthma in school; absenteeism from school due to asthma and treatment options available. We have tried to analyze various treatment modalities of treatment of asthma, allopathy, homeopathy or ayurvedic. Also focus was given to the various types of aerosol therapy, and the parent's perceptions regarding this aerosol therapy. Response options were presented as true/false and unsure.

ii) Asthma attitudes: Asthma attitude was assessed by using Gibson et al. ${ }^{12}$ questionnaire (15 questions) that consists of four domains. The domains assessed were tolerance towards asthmatics (Eight questions), locus of internal control based on the concept of the degree to which a person believes that their own decisions and actions influence their asthma (Two questions), locus of external control or "powerful others" based on the influence of important external people such as a doctor or teacher in their asthma management (Three questions) and chance (Two questions). Responses were presented as six point scale for parents, ranging from "strongly agree" (Scored as 1), to "strongly disagree" (Maximum score). An average score was allocated to each domain. Higher scores represent stronger attitudes in the domains assessed. The Institutional Ethics and Review Board approved the study.

STATISTICAL DATA ANALYSIS: Statistical analysis was performed using SPSS Software version 10. Descriptive statistics were calculated. Mean, median, mode, standard deviation and range were calculated for qualitative variables as mentioned above. Frequencies and percentages were calculated for qualitative variables as mentioned above. Comparison of variables was done using chi-square test. $\mathrm{P}$ value $<0.05$ was considered as significant. 
RESULTS: DEMOGRAPHIC CHARACTERISTICS: The mean age of patients in our study was 51.5 years with slight male preponderance $(54.4 \%)$. The mean duration of illness was 7.5 years. The ratio of urban to rural population was 1.19:1.

KNOWLEDGE ABOUT ETIOLOGY AND THE DISEASE: Out of 160 patients, more than half of the patients did not know that they are suffering from bronchial asthma disease and they had come to know of the diagnosis only at our centre. All these patients were being treated as repeated infections of the respiratory tract with antibiotics. Another half of the patients were labeled as asthma earlier but were not under control, and were having repeated symptoms. About 40.7\% of patients believed it to be some kind of allergy or associated with some allergic cause (Table 1).

Regarding precipitating factors, $46 \%$ of patients could not relate to any cause or factors triggering their disease. Out of remaining 74 patients who were aware of their triggers, $25 \%$ of patients used to avoid them. Some patients had some knowledge about triggering factors in the food items. About $81 \%$ of the patients consider respiratory tract infections as precipitating factor for asthma, while $12 \%$ did not know whether infections can precipitate asthma or not. Another $31.3 \%$ patients told that the respiratory symptoms get exacerbated during the seasonal change, especially during winter climate. Dust was recognized as precipitating factor by $70 \%$ and smoke by $63 \%$ of the patients. About $37.3 \%$ observed that cold drinks aggravated their symptoms, while $46 \%$ identified multiple items to be the triggering event. Only $20 \%$ patients could recognize house mites as precipitating factor while $28 \%$ think that pollens can precipitate asthma.

ASSESSMENT OF KNOWLEDGE AND ATTITUDE: There are lots of misconceptions about asthma in society. The analysis of knowledge results was assessed by the percentage of patients answering each item is as shown in Table 2. A total of $52.5 \%$ of asthma patients said that there are no disadvantages for asthma patients for being in close contact with cats or dogs; $58.1 \%$ some of the medicines used for asthma may have to be used even when I am not having symptoms of asthma; $44.4 \%$ opined that medicines used for asthma attacks constrict air pipes; and $82.5 \%$ said that medicines used for asthma helps in reducing inflammation of air pipes.

The analysis of attitude results was assessed by the percentage of patients answering each item is as shown in Table 3. Regarding the fate of disease, majority of patients $(41 \%)$ were under the wrong belief that asthma is fatal in outcome, while $36.4 \%$ patients believed that their disease is absolutely curable. Only $22.6 \%$ patients believed that their disease is preventable and can be controlled. Nearly half of the patients had sought the help of alternative system of medicine for the control of the disease, with nearly one-third opting for homeopathic treatment before coming to our department.

On an average, each patient had already visited 3 doctors prior to coming to our institution. Oral medications in the form of tablets, capsule, and syrups remained the preferred mode of drug administration in $79 \%$ patients.
This was followed by inhalational route in only $21 \%$ patients. Among inhaled therapy, $56 \%$ patients preferred dry powder inhalers and $44 \%$ patients preferred metered dose inhalers. Out of 160 patients, 63 patients were using inhalers at the time of study. Reasons for reluctance to inhaled therapy were different: some were not advised by the doctor, some find it difficult to use, and $10 \%$ think that inhaled therapy is harmful or addictive. Even among $21 \%$ of patients who were using inhalation therapy, the compliance rate was very low. Table 4 gives all the reasons for discontinuing the inhalation therapy. The most common among these were: attitude towards ill health, stigmatization, and dislike for medications.

DISCUSSION: There is a global problem with asthma management, either under treatment due to ignorance or distorted information/knowledge of patients about their disease. ${ }^{12}$ By 2025, an additional 100 million people will suffer from asthma due, in part, to growing urbanization and pollution. ${ }^{13}$ It is estimated that asthma accounts for about one in every 250 deaths worldwide. The present study showed that the patients with asthma still lack adequate knowledge about the disease and have many misconceptions regarding the illness and its treatment, which needs to be rectified.

The success of any medical regimen prescribed for a particular patient often depends, in large part, on three factors: (a) The patient's knowledge regarding the illness, which enables him/her to take appropriate action to control particular symptoms. (b) The patient's attitude toward the illness, including his or her willingness to work with the physician to manage the disorder and (c) The patient's confidence in his or her ability to contribute to the management of the illness. ${ }^{14}$ Many of the patients refuse to accept the diagnosis of asthma and have poor knowledge about the inhalational form of therapy. They have got many misconceptions regarding the use of inhalers and its usage in everyday practice. Asthma is still a neglected entity unlike other chronic diseases like diabetes mellitus and hypertension. The findings of the present study is similar to that obtained in a recent study done in Lucknow, where it was again observed that the level of awareness regarding asthma was very low among asthmatic patients. ${ }^{15}$ There is a global problem with asthma management, either under treatment due to ignorance or distorted information/knowledge of patients about their disease ${ }^{16}$. Asthma is on rise globally and average asthmatic patient is generally ignorant about his ailment and has misconceptions, which needs to be rectified.

Most of our patients, that is, $80(50 \%)$ were from urban population, but still were ignorant about their disease. Studies have shown that asthma is more prevalent in urban areas than in less polluted areas. ${ }^{17} \mathrm{~A}$ large numbers of patients (68\%) were unaware about the cause of disease, and were also having various wrong beliefs associated with asthma. Other studies by different authors have reported similar findings. ${ }^{18-20}$ The physicians in our hospital disseminated the knowledge of asthma to the patients, and reemphasized that they are suffering from bronchial asthma. This reinforces the need for the role that can be played by media, non-governmental organizations and health workers in heath education regarding asthma. Asthma is still considered like a stigma by the families and proper treatments is not taken unlike other chronic diseases like diabetes mellitus or hypertension. As in the present study many considers it just an allergy (40.7\%), and early treatment is not instituted. This leads to progression of the inflammation in the airways leading to progression of the disease. 
Due to the poor knowledge about the asthma disease, the patients have lot of anxieties. Anxieties about their disease or treatments leave some asthmatics in an unending cycle of poor disease management, fear, symptoms, and resorting to alternative system of medicine in the hope of getting "cured" of asthma. Studies of Kishan and Singh. ${ }^{21}$ and Pradel et al. ${ }^{22}$ also reported that complete trust and positive attitude of the patients towards other therapies for asthma. If patient lacks knowledge regarding asthma, the treatment regimen will fail. In our study, we found out that the patients knowledge regarding the disease was found to be poor, so it is very essential to educate the patients regarding the disease. It is due to misconceptions about asthma drugs usage, $47.5 \%$ of patients don't know about the affect of living together with animals will increase severity of asthma, similar type of results found out were reported in the other studies ${ }^{23}$. Another study ${ }^{24}$ has reported that nearly about $64 \%$ of the patients were ignorant about the etiology of the asthma disease, and $30 \%$ of the patients were reluctant to accept the diagnosis of asthma.

The patients have many misconceptions regarding the diseases and triggers for the asthma. A $44.4 \%$ of asthma patients believed that medicines are going to constrict the bronchi as that it shows how medication will help in managing asthma there is on lack of knowledge regarding the mechanism of action of medicine; $17.5 \%$ of asthma patients were not aware that medication reduces the inflammation. Asthma patients of $45.5 \%$ reported that they stop taking their medication consumption when they feel well or not having symptoms of asthma. But, it is very necessary to educate the patients with asthma to take the medicines regularly as it require long term treatment ${ }^{25}$. Educational methods tailored to needs of each patient and effective behavior towards disease and its management is very essential. In one of our study ${ }^{9}$ it was shown that with various tools of education, the compliance in medications could be increased by almost another $40 \%$.

Attitudes toward asthmatics denoted tolerance, in the sense of a positive and understanding attitude to a person with asthma. The patient has an uncooperative attitude towards treatment problem may arise. The strongest predictors disagree of worry to take their medication for long time, embarrassing in taking their medication in public places. Asthma affects the pleasures of life, others come to know that I have asthma, confident that if I take my medications for asthma regularly, I could live normal life and finally all the medications that I am taking for treating my asthma are essential ${ }^{16}$. Similar types of results were found in the other studies.16,26 Studies have shown that improved knowledge alone does not improve control of asthma. When combined with behavioral therapy the outcome improves. This was observed in the study done by Grover et al. ${ }^{27}$ Patients who dislike taking medication will be more at risk of severe episodes and may be less likely provides their doctors with information important for their management. It clearly shows that a better understanding of attitudes towards asthma medication should be helpful in encouraging good patient adherence to treatment. ${ }^{9}$ It was found that the attitudes of peers towards asthma patients were clearly different from those of the other members in the family. This will lead to anxiety and depression among asthma patients and thus, affecting the compliance to the medications.

Even though inhaler therapy has been accepted as firstline therapy in developed countries, the level of acceptance is poor in our country. Only $39.4 \% \%$ were using inhalational therapy for the control of asthma. Even among them, more than $60 \%$ patients had discontinued inhalers during the course of their treatment. Adherence to asthma medication treatment is inadequate; with figures on low adherent behavior ranging from $38 \%$ to $50 \%{ }^{28}$ Surprisingly in one study. ${ }^{29}$ it was observed that inhalers were considered to be inferior to oral drugs by majority of patients $(76.3 \%)$, rotahalers were used less frequently $(12.1 \%)$ as compared to metered dose inhalers (35.1\%). In another study ${ }^{18}$, it was observed that that majority of patients refused inhaler therapy because they were difficult to use (50.4\%), difficult to carry (48.6\%), habit forming (41.9\%), last resort (38.2\%), and social stigma (36.6\%).

A study on the same subject was also done by the Prasad et al. ${ }^{15}$ about 10 years back; and after analyzing two studies. ${ }^{17,30}$ it was found that there was some improvement in the level of awareness in the patients. Preference to use inhaled drugs had increased from $5.2 \%$ to $36.42 \%$ patients. These figures clearly reflect that we, as physicians, have been partly successful in creating awareness among general public about this disease. In a study. ${ }^{30}$ from Malaysia, most of the parents were concerned about the side effects of inhaled medication in addition to the fear of "inhaler dependency". Other concerns voiced by the parents were the cost of inhaled medication and difficulty in using inhalers. ${ }^{26}$

Recently, Gaude et $\mathrm{al}^{9}$ has observed that the compliance in bronchial asthma patients was just about $38.6 \%$, and even after health education it improved by another $40 \%$. In the present study, only $76 \%$ considered they needed to take all of their medicines to remove all of their breathing problems and more than half of them were afraid to take their medicines.

About $75 \%$ of non-compliers had a tendency to stop their treatment when they felt better, the intermittent nature of asthma is a cause of non-compliance. Similarly in our study the level of adherence to anti-asthmatics were found to be low, $49.5 \%$ of patients said that stopped taking their medication without telling the doctor because they felt worse when took it, and another $34 \%$ of patients stopped their medication when feel health is under control.

Most of the parents usually try oral therapy to control asthma for a variable length of time before switching over to inhaled medication. It has been observed that the frequency of acute exacerbations and yearly hospital visits reduced with inhalation therapy. ${ }^{31}$ There is a misnomer that the inhalers are addictive and should be used as last resort. Hence educating the patients plays an important role in controlling the asthma disease. Even one study which was conducted in Puerto Rican community ${ }^{32}$, it was observed that there was no notable difference in the understanding of asthma between people belonging to opposite ends of the economic or education spectrum. Therefore, it is required to target all segments of society, irrespective of socioeconomic or educational status, and to create better awareness about this disease, so that timely medical advice is sought. 
Education is an essential part of treatment for all asthma patients. Education should not, however, be limited to providing knowledge, but ideally should be aimed at altering behavior.

Physicians and patients need to work together to develop an asthma care program that aims for a life free from asthma symptoms and compromise. By improving asthma knowledge, clarifying wrong beliefs and promoting the basic medical care in asthma exacerbation, we can certainly contribute to the full integration of asthmatics in society to reduce the social and economic costs of asthma. In conclusion, sincere and sustained efforts are required to disseminate knowledge about all aspects of asthma and its management among parents and to dispel their myths and misconception associated with diseases and its therapy.

This will help patients to participate in selfmanagement plans and better control of the asthma in their children. Asthma management is incomplete without a good tailored patient and caregiver's education programs and such programs should be able to augment health education and eliminate misconceptions and stigma in community regarding bronchial asthma.

\section{REFERENCES:}

1. Meza C, Gershwin E. Why is asthma becoming more of a problem? Pulm Med 1997;3:6-9.

2. National Asthma Education and Prevention Program, National Heart, Lung, and Blood Institute: Expert Panel Report 2: Guidelines for the Diagnosis and Management of Asthma, National Institutes of Health Publication No. 97-4051, Bethesda, MD, NHLBI, 1997.

3. Demiralay R. Comparison of the effects of three forms of individualized education on asthma knowledge in asthmatic patients. Turk J Med Sci 2002;32:57-64.

4. Klein JJ, van der Palen J, Uil SM, Zielhuis GA, Seydel ER, Van Herwaarden CL. Benefit from the inclusion of selftreatment guidelines to a self-management programme for adults with asthma. Eur Respir J 2001;17:386-94.

5. Anjan kumar DS, Adepu R, Parthasarathi G, Mahesh PA. Impact of Community Pharmacist Provided Patient Education in Asthma patients on Treatment OutcomesA study. Indian J Pharm Educ Res 2009;43(2):125-33.

6. Franks T J, Burton D L, Simpson M D. Patient medication knowledge and adherence to asthma pharmacotherapy: a pilot study in rural Australia. Therapeutics and Clinical Risk Management 2005;1(1):33-8.

7. Wigal JK, Stout, Brandon M, Winder JA, McConnaughy, Creer $\mathrm{Tl}$ et al. The Knowledge, Attitude, And selfEfficacy Asthma Questionnaire. Chest 1993;104(4):1144-8.

8. Sweileh WM, Arafat RT. Attitudes toward medications: A pilot study in Palestine. Islamic University Journal 2006;14(2):21-30.

9. Gaude GS, Hattiholi J, Chaudhury A. Role of health education and self-action plan in improving the drug compliance in bronchial asthma. J Fam Med Primary Care 2014;3:33-8.
10. Prabhakaran L, Lim G, Abisheganaden J, Chee CBE, Choo YM. Impact os an asthma education programme on patients' knowledge, inhaler technique and compliance to treatment. Singapore Med J 2006;47(3):225-31.

11. Global Initiative for Asthma (GINA). Global Strategy for Asthma Management and Prevention. Updated 2014. Available from: http: //www.ginasthma.com (Accessed on Sept 14, 2015).

12. Gibson PG, Wilson AJ. The use of continuous quality improvement methods to implement practise guidelines in asthma. J Qual Clin Pract 1996;16 87-102.

13. Masoli M, Fabian D, Holt S, Beasley R. Global Initiative for Asthma (GINA) Program. The global burden of asthma: Executive summary of the GINA Dissemination Committee Report. Allergy 2004;59:469-78.

14. Narhi U, Airaksinen M, Tanskanen P, Enlund H. The effects of a pharmacy-based intervention on the knowledge and attitudes of asthma patients. Patient Education and Counseling 2001;43:171-7.

15. Sodhi R, Prasad R, Kushwaha R, Kant S, Verma SK, Garg R, et al. A study to know the knowledge, attitude, and practices of patients of bronchial asthma. Int J Med Public Health 2013;3:159-62.

16. Mahendrakumar BJ, Jimmy Jose, Kumarswamy M, Naveen MR. Assessing the knowledge, attitude and adherence among asthma patients in a rural population. Asian J Pharmac Clinical Research 2011;4(Suppl1):93-97.

17. Prasad R, Gupta R, Verma SK. A study on perception of patients about bronchial asthma. Indian J Allergy Asthma Immunol 2003;17:85-7.

18. Bedi RS. Knowledge about asthma and its management in asthmatics of rural Punjab. Indian J Tub 1993;40:153-5.

19. Pacheco Y, Zureik M, Dussopt C, Thiriet C. Patient knowledge of asthma: Results of a national survey in Pneumology. Rev Pneumol Clin 1999;55:353-63.

20. Shivbalan S, Balasubramanian S, Anandnathan K. What do parents of asthmatic children know about asthma? An indian perspective. Indian $\mathrm{J}$ Chest Dis Allied Sci 2005;47:81-7.

21. Kishan J, Singh A. Knowledge, attitude and practice (KAP) of patients and physician of Bronchial Asthma. Proceedings of XVIII National Congress on Respiratory Diseases, Jalandhar; 1998 Nov 6-7.

22. Pradel FG, Hartzema AG, Bush PJ. Asthma selfmanagement: The perspective of children. Patient Educ Couns 2001;45:199-209.

23. Taylor L. India's asthma market "to grow $10 \%$ a year". Pharma times [online] 2010.

24. Sodhi R, Prasad R, Kushwaha R, Kant S, Verma SK, Garg R, et al. A study to know the knowledge, attitude, and practices of patients of bronchial asthma. Int J Med Public Health 2013;3:159-62.

25. Yoon R, McKenzie DK, Bauman A, Miles DA. Controlled trial evaluation of an asthma education program for adults. Thorax 1993;48:1110-6.

26. Lopez vina A. Attitudes changes needed to foster treatment adherence in patients with asthma.Arch Bronconeumol 2005;41(6):334-340. 
27. Osman LM, Russell, Friend JAR, Legge JS, Douglas JG. Predicting patient attitudes to asthma medication. Thorax 1993;48:827-30.

28. Axelsson M, Emilsson M, Brink E, Lundgren J, Toren K, Lotvall J. personality, adherence, asthma control and health-related quality of life in young adult asthmatics. Respiratory Medicine 2009;103:1033-40.

29. Gupta PP, Gupta KB. Awareness about the disease in asthma patients receiving treatment from physicians at different levels. Indian $\mathrm{J}$ Chest Dis Allied Sci 2001;43:91-5.
30. Brook U, Kishon Y. Knowledge and attitude of healthy high school students toward bronchial asthma and asthmatic pupils. Chest 1993;103:405-7.

31. Hazir T, Das C, Piracha F, Waheed B, Azam M. Carers' perception of childhood asthma and its management in a selected Pakistani community. Arch Dis Child 2002;87:287-290.

32. Zayas LE, Jaen CR, Kane M. Exploring lay definitions of asthma and interpersonal barriers to care in a predominantly Puerto Rican, inner city community. J Asthma 1999;36:527-37.

\begin{tabular}{|c|c|c|}
\hline & Number of patients & $\%$ \\
\hline \multicolumn{3}{|c|}{ Age in years } \\
\hline $18-30$ years & 43 & 26.8 \\
\hline $31-50$ years & 79 & 49.4 \\
\hline$>51$ years & 38 & 23.8 \\
\hline \multicolumn{3}{|c|}{ Gender } \\
\hline Male & 87 & 54.4 \\
\hline Female & 73 & 45.6 \\
\hline \multicolumn{3}{|c|}{ Educational Level } \\
\hline $0-5$ & 32 & 20.0 \\
\hline $5-10$ & 87 & 54.4 \\
\hline Graduate & 41 & 25.6 \\
\hline \multicolumn{3}{|c|}{ Employment Status } \\
\hline Student & 21 & 13.1 \\
\hline Employed & 45 & 28.2 \\
\hline Housewife & 33 & 20.6 \\
\hline Unemployed & 23 & 14.3 \\
\hline Retired & 38 & 23.8 \\
\hline \multicolumn{3}{|c|}{ Duration of Asthma } \\
\hline$<1$ year & 32 & 20.0 \\
\hline $1-2$ years & 21 & 13.1 \\
\hline $3-5$ years & 40 & 25.0 \\
\hline $6-10$ years & 48 & 30.0 \\
\hline$>10$ years & 19 & 11.9 \\
\hline \multicolumn{3}{|c|}{ Table 1: Demographic details of Asthma patients $(n=160)$} \\
\hline
\end{tabular}

\begin{tabular}{|c|c|c|c|}
\hline \multirow{2}{*}{ Questions } & \multicolumn{2}{|c|}{ Answered } & \multirow{2}{*}{$95 \%$ CI } \\
\hline & Yes & No & \\
\hline $\begin{array}{l}\text { Lungs and air pipes are } \\
\text { affected when I have asthma }\end{array}$ & $\begin{array}{c}141 \\
(88.1 \%)\end{array}$ & $\begin{array}{c}19 \\
(11.9 \%)\end{array}$ & $83.2-94.2$ \\
\hline $\begin{array}{l}\text { There are no disadvantages for } \\
\text { asthma patients } \\
\text { for being in close contact with cats or } \\
\text { dogs }\end{array}$ & $\begin{array}{c}84 \\
(52.5 \%)\end{array}$ & $\begin{array}{c}76 \\
(47.5 \%)\end{array}$ & $45.7-55.6$ \\
\hline $\begin{array}{c}\text { Asthma patients may have increase in } \\
\text { symptoms } \\
\text { or attacks of asthma during hot } \\
\text { weather }\end{array}$ & $\begin{array}{c}44 \\
(27.5 \%)\end{array}$ & $\begin{array}{c}116 \\
(72.5 \%)\end{array}$ & $21.2-42.3$ \\
\hline $\begin{array}{l}\text { Coughing and difficulty in breathing } \\
\text { are the common symptoms of asthma } \\
\text { patients }\end{array}$ & $\begin{array}{c}135 \\
(84.3 \%)\end{array}$ & $\begin{array}{c}25 \\
(15.7 \%)\end{array}$ & 78.7-92.1 \\
\hline Smoking can worsen asthma & $\begin{array}{c}123 \\
(76.9 \%) \\
\end{array}$ & $\begin{array}{c}37 \\
(23.1 \%) \\
\end{array}$ & $60.4-81.6$ \\
\hline $\begin{array}{l}\text { Medicines used for asthma attacks } \\
\text { constrict air pipes }\end{array}$ & $\begin{array}{c}71 \\
(44.4 \%) \\
\end{array}$ & $\begin{array}{c}89 \\
(55.6 \%) \\
\end{array}$ & $43.2-72.1$ \\
\hline $\begin{array}{l}\text { Medicines used for asthma helps in } \\
\text { reducing inflammation of air pipes }\end{array}$ & $\begin{array}{c}132 \\
(82.5 \%)\end{array}$ & $\begin{array}{c}28 \\
(17.5 \%) \\
\end{array}$ & $54.5-82.4$ \\
\hline $\begin{array}{c}\text { Some of the medicines used for } \\
\text { asthma may have to be used even } \\
\text { when I am not having symptoms of } \\
\text { asthma }\end{array}$ & $\begin{array}{c}93 \\
(58.1 \%)\end{array}$ & $\begin{array}{c}67 \\
(41.9 \%)\end{array}$ & $54.3-71.3$ \\
\hline
\end{tabular}




\begin{tabular}{|c|c|c|c|c|c|}
\hline \multirow[b]{2}{*}{ Questions } & \multicolumn{4}{|c|}{ Answered } & \multirow[t]{2}{*}{ 95\% CI } \\
\hline & $\begin{array}{c}\text { Strongly } \\
\text { Agree }\end{array}$ & Agree & Disagree & $\begin{array}{l}\text { Strongly } \\
\text { Disagree }\end{array}$ & \\
\hline $\begin{array}{l}\text { Even though I } \\
\text { have asthma, it } \\
\text { does not affect } \\
\text { the pleasures } \\
\text { in my life }\end{array}$ & $\begin{array}{c}36 \\
(22.5 \%)\end{array}$ & $\begin{array}{c}65 \\
(40.6 \%)\end{array}$ & $\begin{array}{c}39 \\
(24.4 \%)\end{array}$ & $\begin{array}{c}20 \\
(12.5 \%)\end{array}$ & 49.7-72.1 \\
\hline $\begin{array}{c}\text { I am not } \\
\text { worried when } \\
\text { others come to } \\
\text { know that I } \\
\text { have asthma }\end{array}$ & $\begin{array}{c}36 \\
(22.5 \%)\end{array}$ & $\begin{array}{c}76 \\
(47.5 \%)\end{array}$ & $\begin{array}{c}37 \\
(23.1 \%)\end{array}$ & $\begin{array}{c}11 \\
(6.9 \%)\end{array}$ & $59.8-82.2$ \\
\hline $\begin{array}{c}\text { If feel, that all } \\
\text { the } \\
\text { medications } \\
\text { that I am } \\
\text { taking for } \\
\text { treating my } \\
\text { asthma are } \\
\text { essential }\end{array}$ & $\begin{array}{c}40 \\
(25.0 \%)\end{array}$ & $\begin{array}{c}61 \\
(38.2 \%)\end{array}$ & $\begin{array}{c}41 \\
(25.6 \%)\end{array}$ & $\begin{array}{c}18 \\
(11.2 \%)\end{array}$ & 78.9-93.2 \\
\hline $\begin{array}{l}\text { I am confident } \\
\text { that if I take } \\
\text { my } \\
\text { medications } \\
\text { for asthma } \\
\text { regularly, I } \\
\text { could live a } \\
\text { normal life }\end{array}$ & $\begin{array}{c}52 \\
(32.5 \%)\end{array}$ & $\begin{array}{c}71 \\
(44.3 \%)\end{array}$ & $\begin{array}{c}25 \\
(15.7 \%)\end{array}$ & $\begin{array}{c}12 \\
(7.5 \%)\end{array}$ & 76.8-91.9 \\
\hline $\begin{array}{c}\text { I am not } \\
\text { embarrassed } \\
\text { in taking my } \\
\text { asthma } \\
\text { medications in } \\
\text { public places, } \\
\text { if I have to } \\
\end{array}$ & $\begin{array}{c}23 \\
(14.4 \%)\end{array}$ & $\begin{array}{c}69 \\
(43.1 \%)\end{array}$ & $\begin{array}{c}47 \\
(29.4 \%)\end{array}$ & $\begin{array}{c}21 \\
(13.1 \%)\end{array}$ & $47.6-78.6$ \\
\hline $\begin{array}{c}\text { I am not } \\
\text { worried even if } \\
\text { I have to take } \\
\text { these } \\
\text { medications } \\
\text { for asthma for } \\
\text { long time }\end{array}$ & $\begin{array}{c}26 \\
(16.3 \%)\end{array}$ & $\begin{array}{c}52 \\
(32.5 \%)\end{array}$ & $\begin{array}{c}64 \\
(40.0 \%)\end{array}$ & $\begin{array}{c}18 \\
(11.2 \%)\end{array}$ & $23.1-36.8$ \\
\hline
\end{tabular}

\begin{tabular}{|c|c|c|}
\hline Reasons & No & \% \\
\hline Cost of medications & 8 & 12.7 \\
\hline Forgetfulness/Complacency & 11 & 17.5 \\
\hline Dislike of medications & 13 & 22.6 \\
\hline Cultural issues & 9 & 14.3 \\
\hline Attitude towards ill health & 15 & 23.8 \\
\hline Awkward regimens & 12 & 19.0 \\
\hline Poor supervision training/follow up & 11 & 17.5 \\
\hline Distant pharmacy & 4 & 6.3 \\
\hline Difficult to carry & 5 & 7.9 \\
\hline Anger about condition and follow up & 12 & 19.0 \\
\hline Stigmatization & 15 & 23.8 \\
\hline Difficulty with inhale devices & 11 & 17.5 \\
\hline Side effects & 12 & 19.0 \\
\hline Lack of response & 9 & 14.3 \\
\hline Others & 5 & 7.9 \\
\hline Table 4: Reasons for discontinuing Inhaler Therapy (n=63)
\end{tabular}

